\title{
Processos Cognitivos na Leitura de Palavras em Crianças: Relações com Compreensão e Tempo de Leitura
}

\author{
Jerusa Fumagalli de Salles ${ }^{12}$ \\ Maria Alice de Mattos Pimenta Parente \\ Universidade Federal do Rio Grande do Sul
}

\begin{abstract}
Resumo
A leitura é composta por múltiplos processos interdependentes. Este estudo analisou o uso preferencial de uma das rotas de leitura (Modelo Cognitivo de Dupla-Rota) e as possíveis relações com compreensão e tempo de leitura em 76 crianças de segunda e terceira séries do Ensino Fundamental de escola particular. Avaliou-se a leitura de palavras isoladas e a compreensão e tempo de leitura textual. Identificou-se quatro grupos segundo as habilidades de leitura de palavras: bons leitores por ambas as rotas; maus leitores por ambas as rotas; leitores preferencialmente lexicais e leitores preferencialmente fonológicos. Os primeiros foram os mais rápidos na leitura textual. Os grupos não diferiram significativamente em compreensão textual, exceto na $3^{a}$ série. Concluiu-se que ambas as rotas de leitura são funcionais na amostra, porém a rota fonológica parece estar melhor desenvolvida do que a rota lexical, que está em expansão, sugerindo um processo de desenvolvimento das habilidades de leitura. Palavras-chave: Leitura; rotas de leitura; compreensão de leitura; modelos cognitivos.
\end{abstract}

Cognitive Processes Involved in Children's Word Reading: Relations with Reading Comprehension and Reading Time

\begin{abstract}
Multiple interdependent processes compose the reading. The present study analyzed the preferential usage on one of the reading routes (Dual Route Cognitive Reading Model) and the possible relations with reading comprehension and reading time in 76 children from second and third grades, in a Elementary private school. The reading of isolated words, comprehension and textual reading time were evaluated. Four groups were identified according with the skills of word reading: good readers in both routes (phonological and lexical), poor readers in both routes, preferably lexical readers and preferably phonological readers. The group of good readers in both routes was the fastest in textual reading. There weren't significant differences among the groups in reading comprehension, except in the third grade. It was concluded that both reading routes were functional in the sample, however the phonological route seems to be better developed than the lexical route, which is in expansion, suggesting a developmental process of the reading skills.

Keywords: Reading; reading routes; reading comprehension; cognitive models.
\end{abstract}

A leitura pode ser estudada sob vários aspectos: sóciocultural, afetivo, pedagógico e cognitivo. O presente estudo baseia-se na abordagem cognitiva da leitura, ou seja, procura desvendar os processos cognitivos subjacentes a esta habilidade, tendo como aportes teóricos a Psicologia Cognitiva, abordagem de Processamento da Informação, e a Neuropsicologia Cognitiva.

Muitos estudos têm sido feitos a respeito da aquisição e desenvolvimento da leitura. Alguns autores nacionais que adotaram os processos de leitura em crianças como tema de pesquisa foram Pinheiro (1994), Capovilla e Capovilla (2000), Cardoso-Martins (1991, 1995), Rego (1995), Kato (1999) e Cielo (1996). Os dois últimos autores adotam uma

\footnotetext{
${ }^{1}$ Endereço para correspondência: Rua Venâncio Aires, 1110/202. Santa Maria, RS. Fones: (51) 99521414 /(55) 30263583.E-mail: jerusa@via-rs.net ${ }^{2}$ Esta pesquisa foi parte integrante da dissertação de Mestrado da primeira autora, apresentada no Programa de Pós-Graduação em Psicologia do Desenvolvimento da UFRGS, sob a orientação da segunda autora.
}

abordagem predominantemente lingüística do tema, enquanto que os primeiros, juntamente com Lecours e Parente (1997), adotam essencialmente a Psicologia Cognitiva como abordagem teórica de base. Lecours e Parente dedicaram-se ao estudo sistemático dos processos cognitivos no leitor adulto de um sistema de escrita alfabético, bem como no estudo das dislexias adquiridas.

Os processos envolvidos na compreensão (leitura) e na produção (escrita) da linguagem escrita são estudados separadamente na Psicologia Cognitiva, pois envolvem processos cognitivos distintos. A leitura parte da informação visual ao som (decodificação), enquanto na escrita os segmentos fonológicos são associados a letras (codificação). Nesta perspectiva, a leitura é uma atividade complexa, composta por múltiplos processos interdependentes, dos quais os fundamentais seriam o reconhecimento de palavras e a compreensão da mensagem escrita (Braibant, 1997; Perfetti, 1992). O primeiro processo envolvido na leitura, reconhecimento de palavras impressas, também 
denominado acesso ao léxico mental, é o acesso à palavra na memória permanente, dado um input gráfico (Perfetti, 1992).

Os processos mentais que permitem ao leitor identificar, compreender e pronunciar palavras escritas são explicados por meio de modelos que enfatizam a estrutura cognitiva envolvida no reconhecimento de palavras e as interconexões dessa estrutura (Pinheiro, 1994). Assim, a leitura em voz alta de um sistema de escrita alfabético pode ocorrer, pelo menos, de duas maneiras: por meio de um processo visual direto (Rota Lexical) ou através de um processo envolvendo mediação fonológica (Rota Fonológica). Recebem, conseqüentemente, o nome de Modelos de Leitura de Dupla Rota (Ellis, 1995; Hillis \& Caramazza, 1992). Ambas rotas de leitura iniciam com o sistema de análise visual, que tem as funções de identificar as letras do alfabeto, a posição de cada letra na palavra, e agrupá-las.

A Rota Fonológica utiliza o processo de conversão grafemafonema, envolvendo a procura de pronúncias para palavras não-familiares e pseudopalavras (formadas por uma combinação de fonemas ou grafemas que não existem no léxico de uma língua) de uma forma serial, traduzindo letras ou grupos de letras em fonemas, através da aplicação de regras. As representações fonêmicas armazenadas ativam as formas fonológicas das palavras que, por sua vez, levam à ativação das representações semânticas e ortográficas correspondentes (Morais, 1996). O fonema é o menor elemento constitutivo da cadeia falada que permite distinções semânticas, enquanto o grafema é a referência gráfica de um fonema.

O uso das regras de conversão grafema-fonema, ou seja, a transposição dos grafemas impressos nos seus respectivos fonemas, deveria permitir uma pronúncia precisa das palavras que possuem correspondência grafia-som regular, mas não de palavras irregulares, o que é conhecido como efeito de regularidade. A leitura por rota fonológica também é fortemente afetada pelo número de letras contidas na palavra, o que é conhecido por efeito de extensão.

$\mathrm{Na}$ leitura, palavras regulares são aquelas cuja estrutura ortográfica possibilita uma leitura por meio de "conversão grafema-fonema unívoca", ou seja, regida por regras. As palavras irregulares, ao contrário, possuem relações grafofonêmicas ambíguas. No português, estas ambigüidades encontram-se apenas diante de um grafema consonantal $(<\mathrm{X}>)$ e de dois vocálicos $(<\mathrm{e}>\mathrm{e}<\mathrm{O}>)$, estes últimos quando estão em posição paroxítona tônica (Parente, Silveira \& Lecours, 1997). A consoante $<X>$ pode ser associada, independentemente da posição, aos fonemas / $\int /, / \mathrm{s} /, / \mathrm{ks} /$ ou $/ \mathrm{z} /$. A vogal $<\mathrm{e}>$ pode ser associada aos fonemas $/ \varepsilon /$ ou /e/, como, por exemplo, nas palavras $<$ festa $>$ e $<$ vespa $>$, enquanto a vogal $<_{\mathrm{O}}>$ pode $s e r$ associada aos fonemas / / ou /o/, como nos exemplos $<$ bosque $>$ e $<$ fosco $>$.

$\mathrm{Na}$ leitura por Rota Lexical, geralmente utilizada por leitores adultos, as representações de milhares de palavras familiares são armazenadas em um léxico de entrada visual, que é ativado pela apresentação visual de uma palavra. Isto é seguido pela obtenção do significado a partir do sistema semântico (depósito de todo o conhecimento sobre os significados de palavras familiares) e, então, a palavra pode ser articulada. Pessoas que utilizam apenas esta rota têm pouca ou nenhuma dificuldade em pronunciar palavras familiares, entretanto, encontram muita dificuldade com palavras relativamente não-familiares e pseudopalavras.

Através da rota lexical, palavras de alta freqüência de ocorrência na língua são reconhecidas com maior rapidez e precisão do que palavras de baixa freqüência, o que é conhecido como efeito de frequiência. A presença de um efeito de lexicalidade, ou seja, palavras reais sendo identificadas mais rápida e precisamente do que pseudopalavras, é outro indício de leitura por rota lexical. As palavras, quando familiares, têm unidades de reconhecimento no léxico de entrada visual, o que não ocorre com as pseudopalavras (Ellis, 1995).

Considerando o Modelo de Leitura de Dupla-Rota, leitores que usam preferencialmente a rota lexical têm maior facilidade na leitura de palavras irregulares do que na leitura de pseudopalavras, enquanto que leitores que usam preferencialmente a rota fonológica têm maior facilidade na leitura de palavras regulares e pseudopalavras do que na leitura de palavras irregulares.

A avaliação dos processos envolvidos na leitura, em uma abordagem de Processamento da Informação, consiste no uso de procedimentos que possibilitem a determinação do estado operacional e do modo de funcionamento de cada componente do modelo cognitivo. Esses procedimentos caracterizam-se pela apresentação de listas de palavras que variam nas suas propriedades lingüísticas: freqüência de ocorrência na língua; regularidade da correspondência grafema-fonema; concretude; extensão, lexicalidade e classe gramatical (Pinheiro \& Parente, 1999).

No leitor hábil, as duas rotas estão disponíveis e podem intervir paralelamente na leitura de palavras (Morais, 1996). Tanto as características lingüísticas do estímulo, como o nível de competência do leitor determinam o tipo de processo a ser usado (Pinheiro \& Parente, 1999). Pinheiro (1994), estudando as habilidades de leitura e escrita de crianças brasileiras de $1^{\text {a a }} 4^{\text {a }}$ série, constatou o uso de processos lexicais e, predominantemente, fonológicos em estágios iniciais do desenvolvimento de leitura. Seus resultados sugerem que ambos processos devem desenvolver-se simultaneamente. 
Apenas o procedimento fonológico é gerativo, isto é, capaz de permitir a identificação das palavras encontradas pela primeira vez ou palavras para quais não está disponível uma representação ortográfica na memória. Graças a esta propriedade de gerativismo, a rota fonológica constitui um elemento essencial na aquisição da leitura (Alégria, Leybaert \& Mousty, 1997). De acordo com a hipótese de autoensinamento (Share, 1995), cada encontro de decodificação bem sucedido com uma palavra não familiar provê uma oportunidade para adquirir informação ortográfica, que é o fundamento do reconhecimento hábil de palavra.

A leitura não envolve apenas o reconhecimento de palavras isoladas. Seu objetivo principal é a compreensão do material lido. Para isso, a identificação de palavras é uma condição necessária, embora não seja suficiente (Alégria \& cols., 1997). A compreensão da leitura requer capacidades cognitivas, como a elaboração de inferências, e lingüísticas, como conhecimento do vocabulário, da sintaxe, entre outras (Braibant, 1997).

A literatura sugere uma relação entre automatismo (precisão e rapidez) no reconhecimento de palavras e compreensão de leitura (Alégria \& cols., 1997; Morais, 1996; Perfetti \& Hogaboam, 1975). Quanto mais rápida for a identificação de cada palavra, maior a capacidade da memória de trabalho consagrada às operações de análise sintática, de integração semântica dos constituintes da frase e de integração das frases na organização textual, processos importantes para a compreensão da leitura (Morais, 1996).

Além do automatismo na identificação de palavras, para compreender um texto é necessário empregar conhecimentos e estratégias que vão mais além da mera combinação de significados lexicais individuais, é necessário elaborar uma representação mental do conteúdo proposicional das mensagens. Proposições são unidades abstratas de significado e implicam, no mínimo, a predicação de algo (uma propriedade, ação, relação, etc.) acerca de algo (um objeto, argumento, etc.) (Kintsch, 1998).

Kintsch e van Dijk (1978) propõem um Modelo de Compreensão de Textos segundo o qual, devido às limitações na memória de curto prazo, o processamento de um texto é feito em ciclos, que correspondem, aproximadamente, a uma frase. Destes ciclos, uma estrutura mais geral de significado, a macroestrutura, é extraída das proposições do texto original e mantida na memória episódica junto com os itens finais do ciclo. As frases apresentadas no texto são conhecidas como microestruturas. O ciclo seguinte altera as representações dos anteriores na memória episódica, fazendo com que ocorra a construção gradual de um texto base.

A noção de macroestrutura é empregada por Kintsch e van Dijk (1978) para definir a descrição semântica do conteúdo global do discurso. Pode ser entendida como uma certa organização de significado que representa os aspectos essenciais de um texto, por meio de unidades denominadas macroproposições. A compreensão pode ser entendida como um processo que permite elaborar a macroestrutura do texto a partir de sua microestrutura. No processamento e retenção da informação textual, as macroproposições têm maior probabilidade de serem lembradas e incluídas em resumos (Kintsch, 1998).

Van Dijk e Kintsch (1983, citados em Denhière \& Baudet, 1992) distinguem três níveis na representação do discurso: 1) a estrutura de superfície (palavras e sintagmas utilizados no texto); 2) o conteúdo semântico local (microestrutura) e global (macroestrutura); e, 3) o modelo de situação. Neste último, o que é representado é a situação descrita no texto, retirada da estrutura do texto e encaixada no campo de conhecimentos pré-estabelecidos do sujeito, o que envolve também a elaboração de inferências.

Em síntese, a compreensão textual inclui vários processos cognitivos interrelacionados. Entre eles, os processos básicos de leitura, como o reconhecimento e extração do significado das palavras impressas, são requisitos necessários, mas não suficientes. Uma compreensão textual bem sucedida exige processos cognitivos de alto nível, como capacidade de realizar inferências, habilidades lingüísticas gerais, habilidades de memória, conhecimento de mundo, que juntos contribuem para a construção de uma representação macroestrutural do texto.

Considerando os vários processos envolvidos na habilidade de ler, este estudo teve por objetivos 1) analisar a validade dos modelos cognitivos de leitura de dupla-rota em uma amostra de crianças em início de segunda e terceira séries do Ensino Fundamental; 2) analisar o uso preferencial sobre uma das rotas de leitura; e, 3) as possíveis relações com compreensão e tempo de leitura textual. Pretende-se, dessa forma, contribuir para o avanço dos conhecimentos teóricos e das práticas de avaliação da leitura em crianças, apresentando um paradigma emergente, o Processamento de Informação.

\section{Método}

\section{Participantes}

Participaram deste estudo 76 crianças, de ambos os sexos, com idades entre 6 anos e 9 meses e 9 anos e 4 meses $(m=8,1)$, estando 40 delas em início de segunda e 36, em início de terceira série do Ensino Fundamental de uma escola particular, que atende uma população de classe sócioeconômica média- alta. Nas amostras de segunda e terceira séries, as médias de idade foram, respectivamente, 7,6 e 8,6 anos. 
A amostra caracterizou-se por crianças não repetentes na escola; sem queixas de problemas auditivos ou dificuldades visuais não corrigidas; e com linguagem expressiva oral dentro dos padrões considerados normais para a idade. A linguagem foi avaliada através de situação dialógica informal e pelas informações fornecidas por pais e professores. Algumas crianças apresentaram desvio articulatório, sendo encaminhadas para atendimento fonoaudiológico, e nenhuma apresentou desvio fonológico, o que justificaria sua exclusão da amostra. Todas as crianças estavam autorizadas pelos pais ou responsáveis a participar da pesquisa.

As crianças provinham de uma escola particular de abordagem construtivista. Através de entrevista com os professores a respeito do método de ensino de leitura, podese perceber que os professores instruem tanto a leitura global da palavra auxiliada pelo contexto semântico do texto, quanto à decodificação de palavras que não são identificadas global e automaticamente.

\section{Instrumentos e Procedimentos}

As crianças foram avaliadas, individualmente, no início do período letivo, em uma única sessão, quanto às suas habilidades de leitura de palavras isoladas, compreensão e tempo de leitura textual.

Avaliação da leitura de palavras isoladas

Esta avaliação foi realizada com o intuito de analisar a(s) rota(s) preferencialmente usada(s) na leitura de palavras isoladas, considerando o Modelo de Leitura de Dupla-Rota. Para isso, foram construídas duas listas de estímulos, uma para cada série escolar. Cada lista era composta por igual número de palavras regulares, irregulares e pseudopalavras, totalizando 60 estímulos, que variavam em extensão: estímulos curtos (até cinco letras) e longos (oito ou mais letras). As palavras reais variavam também quanto à freqüência de ocorrência na língua portuguesa, segundo a lista de freqüência de ocorrência de palavras expostas a crianças na faixa de pré-escola e séries iniciais (Pinheiro, 1996). As pseudopalavras foram formuladas considerando as convenções grafofonêmicas e a estrutura silábica da língua portuguesa. Portanto, elas podem ser lidas em voz alta, mas carecem de significado.

A apresentação dos estímulos foi realizada através do computador, utilizando o Programa Psychlab (Bub \& Gum, 1988). Foi computado o número de respostas corretas em cada lista de estímulos (precisão na leitura). As respostas incorretas foram enquadradas em uma ou mais das sete categorias seguintes:

1) neologismo: ocorrem omissões, acréscimos, transposições e/ou substituições de fonemas, que não geram palavras reais (Ex.: atmosfera lido como "atomosfera"; "alanare" lido como "analare");
2) regularização: a pronúncia grafema-fonema irregular de uma palavra é substituída por uma pronúncia regular e mais freqüente da correspondência em questão em dado contexto (Ex.: boxe lido como "boche").

3) desconhecimento de regra ortográfica: pronúncia incorreta devido ao desconhecimento de certas regras contextuais da língua portuguesa, como casa lida como "cassa";

4) desconhecimento de regra de acentuação: a pronúncia das palavras não leva em conta as regras de acentuação (Ex.: parágrafo lido como "paragráfo");

5) paralexia verbal formal: substituição lexical mantendo uma semelhança de estrutura de letras, mas sem relação semântica (Ex.: grade lido como "grande");

6) lexicalização: uma pseudopalavra é lida como uma palavra real, mantendo relações de semelhança formal (Ex.: "azercico" lida como "exercício");

7) não resposta: não é enunciada nenhuma pronúncia ao estímulo apresentado.

Além da porcentagem de respostas corretas em cada lista de estímulos, também foram comparados os resultados do desempenho da amostra nas diversas categorias de estímulos através da análise dos efeitos de freqüência (porcentagem de acertos na leitura de palavras freqüentes menos a porcentagem de acertos na leitura de palavras não-freqüentes), regularidade (acertos na leitura de palavras regulares menos acertos na leitura de palavras irregulares), extensão (acertos na leitura de palavras curtas menos acertos na leitura de palavras longas) e lexicalidade (acertos na leitura de palavras reais menos acertos na leitura de pseudopalavras).

\section{Avaliação da compreensão de leitura}

Cada criança era solicitada a ler silenciosamente uma história, com extensão de aproximadamente 200 palavras e níveis apropriados de legibilidade para a escolaridade da amostra (Rocha, 1997). A compreensão de leitura foi avaliada de duas formas: através da reprodução oral da história lida (reconto) e através da resposta a questões de múltipla escolha sobre a história.

No primeiro procedimento, cada criança foi instruída a recontar a história com a maior quantidade de detalhes possível. Os recontos foram analisados segundo o Modelo de Compreensão Textual de Kintsch e van Dijk (1978). Neste modelo, o significado do texto original é representado através de uma lista estruturada de proposições, que são classificadas conforme sua importância para a compreensão da história, como: fazendo parte apenas da microestrutura (detalhes menos relevantes) ou também da macroestrutura (idéias essenciais) do texto. A história proposta foi dividida, através de acordo entre quatro juizes, em 61 proposições, sendo 23 consideradas como integrando a macroestrutura e 38 , a microestrutura menos relevante do texto. 
No reconto de cada criança, as proposições do texto original relatadas foram classificadas em porcentagem total de proposições presentes, porcentagem de macroproposições e de microproposições menos relevantes relatadas. As proposições emitidas nos recontos que não estavam presentes na história original foram classificadas em inferências (comentários pertinentes sobre fatos presentes na história original ou relato de um fato que deve ter acontecido na história, mas que estava ausente no texto original), interferências (modificação do significado das proposições da história por associação, em uma mesma proposição, de dois elementos presentes na história, mas independentes) ou reconstruções (introdução de proposições que relatavam fatos não presentes na história original)(Parente, Capuano \& Nespoulous, 1999).

O segundo procedimento de avaliação era composto por 10 perguntas sobre a história, cada uma delas acompanhada de cinco itens-resposta. Metade das perguntas era relacionada com memória para eventos e personagens descritos na própria história e a outra metade avaliava compreensão inferencial. Os resultados foram apresentados em termos de porcentagem de questões respondidas corretamente.

\section{Avaliação do tempo de leitura de texto}

As crianças foram solicitadas a ler em voz alta uma segunda história, de complexidade semelhante à primeira, composta por 93 palavras. Foi medido o tempo (em segundos) transcorrido entre o início e o final da leitura.

\section{Resultados}

\section{Precisão na Leitura de Palavras Isoladas}

A formação de grupos por habilidades de leitura de palavras (rotas de leitura) baseou-se no método proposto por Freebody e Byrne (1988). O desempenho da amostra total na leitura de palavras regulares, irregulares e pseudopalavras foi submetido a uma análise de cluster (Johnson \& Wichern, 1998). Foram identificados quatro grupos de leitores. A formação de cada grupo por série é apresentada da Tabela 1 e o desempenho na leitura de palavras desses grupos, na Tabela 2. O Grupo BA (bons leitores por ambas as rotas de leitura) obteve média de acertos superior à média total da amostra em todas as categorias de estímulos. O Grupo PL (leitores preferencialmente lexicais) identificou mais precisamente palavras reais do que pseudopalavras. O Grupo PF (leitores preferencialmente fonológicos) identificou, com maior precisão, palavras regulares e pseudopalavras do que palavras irregulares, sendo formado predominantemente por alunos da segunda série $(88,23 \%)$. Por fim, o Grupo MA (maus leitores por ambas as rotas de leitura) apresentou desempenho inferior à média da amostra em todas as categorias de estímulos.

Tabela 1

Número e Porcentagem de Participantes em cada um dos Quatro Grupos de Leitores, segundo a Série Escolar

\begin{tabular}{lrrrrrr}
\hline Grupos & Amostra de $2^{\mathrm{a}}$ série & \multicolumn{2}{c}{ Amostra de $3^{\mathrm{a}}$ série } & \multicolumn{2}{c}{ Amostra total } \\
de leitores & $N$ & $\%$ & $N$ & $\%$ & $N$ & $\%$ \\
\hline Grupo BA & 12 & 30,0 & 25 & 69,4 & 37 & 48,7 \\
Grupo PL & 8 & 20,0 & 5 & 13,9 & 13 & 17,1 \\
Grupo PF & 15 & 37,5 & 2 & 5,6 & 17 & 22,4 \\
Grupo MA & 5 & 12,5 & 4 & 11,1 & 9 & 11,8 \\
\hline Total & 40 & 100,0 & 36 & 100,0 & 76 & 100,0 \\
\hline
\end{tabular}

Nota. $\mathrm{BA}=$ bons leitores por ambas rotas; $\mathrm{PL}=$ leitores preferencialmente lexicais; $\mathrm{PF}=$ leitores preferencialmente fonológicos, e MA = maus leitores por ambas rotas.

Tabela 2

Média e Desvio-padrão da Porcentagem de Acertos na Leitura de Palauras Total e em cada Categoria de Estímulos, por Grupo de Leitores

\begin{tabular}{lllll}
\hline $\begin{array}{l}\text { Grupos } \\
\text { de leitores }\end{array}$ & $\begin{array}{l}\text { Regular } \\
\text { média } \pm d p\end{array}$ & $\begin{array}{l}\text { Irregular } \\
\text { média } \pm d p\end{array}$ & $\begin{array}{l}\text { Pseudopalavra } \\
\text { média } \pm d p\end{array}$ & $\begin{array}{l}\text { Total estímulos } \\
\text { média } \pm d p\end{array}$ \\
\hline Grupo BA & $96,35 \pm 3,47^{\mathrm{a}}$ & $92,57 \pm 5,35^{\mathrm{a}}$ & $88,78 \pm 7,58^{\mathrm{a}}$ & $92,57 \pm 3,35^{\mathrm{a}}$ \\
Grupo PL & $90,0 \pm 4,08^{\mathrm{b}}$ & $73,46 \pm 13,75^{\mathrm{b}}$ & $65,77 \pm 11,70^{\mathrm{b}}$ & $76,41 \pm 7,07^{\mathrm{b}}$ \\
Grupo PF & $90,29 \pm 5,72^{\mathrm{b}}$ & $67,35 \pm 7,73^{\mathrm{b}}$ & $89,12 \pm 5,07^{\mathrm{a}}$ & $82,25 \pm 3,72^{\mathrm{c}}$ \\
Grupo MA & $78,33 \pm 7,50^{\mathrm{c}}$ & $42,77 \pm 11,75^{\mathrm{c}}$ & $75,56 \pm 11,58^{\mathrm{c}}$ & $65,56 \pm 6,18^{\mathrm{d}}$ \\
\hline Total $(n=76)$ & $91,78 \pm 7,38$ & $77,76 \pm 18,82$ & $83,35 \pm 12,34$ & $84,3 \pm 10,39$ \\
\hline
\end{tabular}

Nota. $\mathrm{BA}=$ bons leitores por ambas rotas; PL $=$ leitores preferencialmente lexicais; $\mathrm{PF}=$ leitores preferencialmente fonológicos e $\mathrm{MA}=$ maus leitores por ambas rotas. a, b, c, d $=$ médias $( \pm$ desvio-padrão $)$ seguidas de letras iguais não diferem significativamente ao nível de 5\% entre os Grupos de Leitores (One-Way ANOVA). 
Estes resultados evidenciam que quase metade da amostra total apresentou bom desempenho na leitura de palavras independente do tipo de estímulo (Grupo BA), ou seja, usava de forma proficiente tanto a rota de leitura fonológica quanto a lexical, enquanto que algumas crianças faziam uso preferencial de uma das rotas em detrimento de outra. $\mathrm{Na}$ amostra de segunda série, houve uma predominância de sujeitos nos grupos $\mathrm{PF}$ e BA, enquanto que na terceira série a grande maioria das crianças encontravase no Grupo BA.

A comparação do desempenho na leitura de palavras entre os grupos de leitores mostrou diferenças estatisticamente significantes entre as médias de acertos no total do teste $(F(3,72)=103,09 ; p<0,001)$, na leitura de palavras regulares $(F(3,72)=37,05 ; p<0,001)$, irregulares $(F(3,72)=94,93 ; p<0,001)$ e pseudopalavras $(F(3,72)=28,74$; $p<0,001)$. No total de estímulos da tarefa, os bons leitores de acertos no total da tarefa de leitura de palavras isoladas $(F(1,70)=9,14 ; p<0,01)$ e na leitura de palavras irregulares $(F(1,70)=9,27 ; p<0,01)$. Alunos da $3^{\text {a }}$ série apresentaram desempenho superior ao dos alunos da $2^{a}$ série. A média de acertos das crianças da $2^{\mathrm{a}}$ e $3^{\mathrm{a}}$ séries no total da tarefa de leitura de palavras foi, respectivamente, $81,62 \%(d p=10,41)$ e $87,27 \%(d p=9,67)$. Na leitura de palavras irregulares, os primeiros acertaram, em média, 71,25\% $(d p=18,90)$ dos estímulos, enquanto os últimos acertaram, em média, $85,0 \%$ $(d p=16,08)$.

O fator faixa etária também foi considerado no estudo. Houve diferenças significantes entre as médias da porcentagem de acertos total na leitura de palavras $(F(1,70)=4,34 ; p<0,05)$ e na leitura de pseudopalavras $(F(1,70)=6,5 ; p<0,05)$ entre crianças com idade superior a 8 anos e aquelas com idade inferior a 8 anos. No total da tarefa de leitura de palavras, as mais velhas apresentaram

Tabela 3

Média e Desvio-padrão dos Efeitos de Freqüência, Extensão, Regularidade e Lexicalidade, segundo a Série Escolar

\begin{tabular}{lccc}
\hline & $\begin{array}{c}\text { Amostra de } 2^{\text {a }} \text { série } \\
(n=40)\end{array}$ & $\begin{array}{c}\text { Amostra de } 3^{\text {a }} \text { série } \\
(n=36)\end{array}$ & $\begin{array}{c}\text { Amostra total } \\
(n=76)\end{array}$ \\
\hline média $+d p$ & média $+d p$ & média $+d p$ \\
Efeito de freqüência & $13,5 \pm 8,78$ & $7,08 \pm 10,24$ & $10,46 \pm 9,97$ \\
Efeito extensão palavra real & $6,0 \pm 9,41$ & $-2,08 \pm 7,4$ & $2,17 \pm 9,39$ \\
Efeito extensão pseudopalavra & $16,0 \pm 16,61$ & $11,67 \pm 18,59$ & $13,95 \pm 17,59$ \\
Efeito de regularidade & $19,25 \pm 16,07$ & $8,19 \pm 11,28$ & $14,01 \pm 14,99$ \\
Efeito de lexicalidade & $-2,25 \pm 14,34$ & $5,49 \pm 11,78$ & $1,41 \pm 13,67$ \\
\hline
\end{tabular}

por ambas as rotas (BA) apresentaram o melhor desempenho, seguido do grupo de leitores preferencialmente fonológicos (PF). Comparando os grupos em que houve uso preferencial de uma das rotas de leitura, leitores que usavam preferencialmente a rota fonológica desempenharam esta tarefa com maior precisão do que leitores preferencialmente lexicais.

$\mathrm{Na}$ análise dos efeitos de freqüência, extensão, regularidade e lexicalidade (Tabela 3), o maior efeito encontrado foi o de regularidade, seguido pelo efeito de extensão na leitura de pseudopalavras. Ambos são indicativos do uso da rota fonológica. Outro indicativo do maior uso da rota fonológica é efeito de lexicalidade quase inexistente, demonstrando que as crianças podem ler tanto palavras quanto pseudopalavras da mesma forma, ou seja, através da rota fonológica. O terceiro maior efeito encontrado foi o de freqüência, que é um dos indicativos do uso da rota lexical.

Considerando o fator série escolar, houve diferenças estatisticamente significantes entre as médias da porcentagem desempenho superior $(m=84,88 \% ; d p=11,73)$ ao das mais novas $(m=83,44 ; d p=8,17)$, enquanto que, na leitura de pseudopalavras, este padrão inverteu-se. $\mathrm{Na}$ leitura de pseudopalavras, crianças com idade inferior a 8 anos apresentaram escore médio de $93,23 \%(d p=8,32)$, enquanto que nas crianças com idade superior a 8 anos este escore foi de $88,0 \%$ ( $(p=13,07)$.

$\mathrm{Na}$ análise qualitativa dos erros, aqueles de maior ocorrência foram neologismo $(m=30,9 \%)$, regularização $(m=30,7 \%)$ e desconhecimento de regra ortográfica $(m=12,0 \%)$. Pelas suas características, esses tipos de erros sugerem maior uso da rota fonológica na leitura de palavras. Neologismos, por exemplo, podem indicar que o sujeito falhou no uso de regras de correspondência grafemafonema, quando na leitura por rota fonológica.

Houve diferenças significantes entre os grupos de leitores apenas nos erros de regularização $(F(3,72)=10,54 ; p<0,001)$. Este tipo de erros foi menos freqüente em leitores preferencialmente lexicais $(m=23,5 \%)$ e no Grupo BA $(m=23,28 \%)$ do que em leitores preferencialmente 
fonológicos $(m=47,2 \%)$. Isto indica que a leitura de palavras irregulares por rota fonológica implica em erros de regularização, confirmando a superioridade do uso desta rota no Grupo PF. Os erros de lexicalização foram significativamente mais freqüentes $(F(1,70)=6,22 ; p<0,05)$ em alunos da $3^{\mathrm{a}}$ série $(m=10,72 \%)$ do que alunos da $2^{\mathrm{a}}$ série $(m=3,04 \%)$.

\section{Compreensão e Tempo de Leitura Textual}

$\mathrm{Na}$ análise dos recontos da história, observou-se que a amostra relatou, em média, $21,07 \%$ da estrutura proposicional geral da história. Em estudos experimentais (Kintsch, 1977), foram encontrados que os sujeitos retêm, aproximadamente, de 10 a $25 \%$ de uma história, reproduzindo não apenas um fragmento do texto original, mas também uma versão mais abstrata. Foram relatadas, no presente estudo, maior porcentagem de macroproposições $(m=31,9 \%)$ do que de microproposições menos relevantes $(m=14,5 \%)$ da história, evidenciando uma compreensão e retenção da essência da mesma, mais do que dos detalhes menos relevantes.

A compreensão de um texto não se resume à capacidade de memória, mas também à capacidade de inferir fatos que não são apresentados explicitamente no texto (Brandão \& Spinillo, 1998). Os recontos da história deste estudo apresentaram maior número de inferências $(m=2,26$; $d p=1,63)$ e menor número de reconstruções $(m=1,38$; $d p=1,46)$ e de interferências $(m=1,24 ; d p=1,24)$, mostrando que as crianças extraíram também as idéias implícitas na história e, em geral, mantiveram-se fiéis ao significado original da mesma. A amostra, em média, apresentou desempenho elevado no procedimento de responder a questões sobre a história ( $m=81,71 \%$ de respostas corretas).

Não houve diferença significativa entre as médias dos quatro Grupos de Leitores nas variáveis estudadas no reconto da história, exceto na amostra de $3^{a}$ série. Nesta amostra, houve diferença significativa no número de interferências entre os Grupos de Leitores $(F(3,32)=7,71$; $p<0,01)$. O Grupo PF apresentou o maior número de interferências $(m=5,0)$, enquanto o restante dos grupos não diferiu significativamente entre si. Este resultado deve ser interpretado com cautela, devido ao pequeno número de integrantes no grupo de leitores preferencialmente fonológicos na $3^{\mathrm{a}}$ série (apenas 2).

Considerando o fator série escolar, alunos da $3^{a}$ série relataram significativamente $(F(1,70)=4,24 ; p<0,05)$ maior porcentagem de microproposições menos relevantes do texto $(m=17,1 \%)$ do que alunos da segunda série $(12,17 \%)$. $\mathrm{Na}$ tarefa de compreensão de questões, não houve diferença de desempenho entre os grupos de leitores, porém o desempenho das crianças de $3^{\text {a }}$ série $(m=86,67 \%)$, mais uma vez, foi significativamente superior $(F(1,70)=5,06 ; p<0,05)$ ao das crianças de $2^{\mathrm{a}}$ série $(m=77,25 \%)$.

Quanto ao tempo de leitura, houve uma ampla variabilidade interindividual entre os grupos de leitores, com diferenças estatisticamente significantes entre as médias de cada grupo $(F(3,72)=24,45 ; p<0,001)$. Os Grupos BA e MA diferiram significativamente de todos os outros grupos e entre si, enquanto que os Grupos PL e PF apresentaram resultados semelhantes e intermediários. Os sujeitos que usavam eficientemente ambas as rotas de leitura foram os mais rápidos na leitura textual $(m=54,38)$, enquanto que o grupo de maus leitores por ambas as rotas foram os mais lentos $(m=152,78)$.

No processo de identificação de palavras, o uso da Rota Lexical permite acesso mais rápido ao léxico mental por ser um procedimento de acesso direto ao significado à partir da estrutura gráfica. Ao contrário, a Rota Fonológica é um procedimento seqüencial, ao menos no início do desenvolvimento da leitura, e, portanto, mais lento do que o anterior. Sendo assim, uma hipótese seria que o uso preferencial da rota lexical levaria a uma maior velocidade de leitura textual e, como conseqüência, uma melhor compreensão de leitura. Apenas na amostra de terceira série houve diferença estatisticamente significante entre os grupos PL e PF $(F(3,32)=12,71 ; p<0,001)$. Os leitores preferencialmente fonológicos foram mais lentos $(m=130,0)$ do que os leitores preferencialmente lexicais $(m=82,80)$. Ao menos nesta série, o maior uso do acesso direto ao léxico mental proporcionou uma leitura textual mais veloz do que a aplicação das regras de correspondência grafema-fonema. Porém, novamente, os leitores mais velozes foram os que usavam proficientemente ambas as rotas de leitura $(m=53,32)$.

As crianças da $2^{\mathrm{a}}$ série foram significativamente mais lentas $(m=102,87)$ do que as crianças da $3^{\text {a }}$ série $(m=67,81)$ na leitura textual $(F(1,70)=18,11 ; p<0,001)$, o que pode ser justificado pelo fato de que a maioria destas últimas usarem proficientemente ambas as rotas de leitura.

\section{Correlações entre as Avaliações}

A matriz de correlações entre as avaliações realizadas é mostrada na Tabela 4. Precisão na leitura de palavras isoladas correlacionou-se de forma fraca com compreensão de leitura, mas apresentou forte correlação negativa com tempo de leitura textual $(r=-0,79)$. Este resultado indica que quanto mais precisa é a leitura de palavras, menor é o tempo gasto para ler um texto, sugerindo uma relação entre precisão na leitura de palavras isoladas e velocidade de leitura textual. $\mathrm{Na}$ leitura em contexto, segundo Perfetti (1992), a maioria das palavras são acessadas uma de cada vez e saltamos muito poucas palavras. Tempo de leitura textual apresentou 
Tabela 4

Matriz de Correlações entre as Avaliações Realizadas

\begin{tabular}{lllllllll}
\hline & 1 & 2 & 3 & 4 & 5 & 6 & 7 & 8 \\
\hline 1. Precisão leitura palavras & - & - & - & - & - & - & - & - \\
2. Leitura palavras regulares & $0,76^{* *}$ & - & - & - & - & - & - & - \\
3. Leitura palavras irregulares & $0,91^{* *}$ & $0,66^{* *}$ & - & - & - & - & - & - \\
4. Leitura pseudopalavras & $0,69^{* *}$ & $0,31^{* *}$ & $0,37^{* *}$ & - & - & - & - & - \\
5. Compreensão questões & $0,29^{*}$ & $0,27^{*}$ & $0,29^{*}$ & 0,12 & - & - & - & - \\
6. Proposições (\%) & $0,29^{*}$ & $0,25^{*}$ & $0,29 *$ & 0,14 & $0,5^{* *}$ & - & - & - \\
7. Macroproposições (\%) & $0,32^{* *}$ & $0,29 *$ & $0,32^{* *}$ & 0,15 & $0,52^{* *}$ & $0,91^{* *}$ & - & - \\
8. Microproposições (\%) & 0,19 & 0,15 & 0,2 & 0,09 & $0,38^{* *}$ & $0,89^{* *}$ & $0,62^{* *}$ & - \\
9. Tempo de leitura & $-0,79^{* *}$ & $-0,64^{* *}$ & $-0,79 * *$ & $-0,41^{* *}$ & $-0,31^{* *}$ & $-0,28^{*}$ & $-0,32^{* *}$ & $-0,17$ \\
\hline
\end{tabular}

Nota. $^{*}=p<0,05 ; * *=p<0,01$

correlações negativas moderadamente fracas com compreensão de leitura $(r=-0,32)$. Leitores mais velozes tendem a apresentar melhores habilidades de compreensão de leitura.

As correlações significativas encontradas entre precisão na leitura de palavras regulares, irregulares e pseudopalavras demonstram que, em geral, as crianças que apresentaram um bom desempenho na leitura de palavras reais também apresentaram na leitura de pseudopalavras.

\section{Discussão}

O fato de haver maior proporção de crianças de $2^{\mathrm{a}}$ série que usavam preferencialmente a rota fonológica ou que usavam ambas as rotas reforça a importância das habilidades de decodificação no início da aquisição da leitura e sugere um processo de desenvolvimento, inicialmente caracterizado pelo maior uso da rota fonológica. Em início de segunda série, a criança parece ainda não ter um extenso vocabulário de palavras identificadas de forma direta, sem mediação fonológica, que a permitiria usar preferencialmente a rota lexical na leitura de palavras. Com isso, neste período, o uso da rota fonológica, pelas suas propriedades de gerativismo e de auto-ensinamento (Share, 1995), seria imprescindível para a expansão do léxico ortográfico da criança, pois proporcionaria oportunidade para a aquisição de informação ortográfica.

A grande maioria das crianças de $3^{a}$ série deste estudo encontrava-se no grupo de bons leitores por ambas as rotas (BA), seguido daquelas que usavam preferencialmente a rota lexical (PL). Uma mínima proporção de crianças (apenas duas) usava preferencialmente a rota fonológica ou eram maus leitores por ambas as rotas. Pode-se perceber, então, uma tendência desenvolvimental da segunda para a terceira série, ou seja, crianças com um ano a mais de escolaridade são mais capazes de identificar precisamente qualquer tipo de estímulo, pois usam com maior habilidade ambas as rotas de leitura de palavras. Na segunda série, é grande a porcentagem de crianças que usam preferencialmente a rota fonológica, considerada importante no início do período de alfabetização.

Esses resultados sugerem que a leitura por rota fonológica pode evoluir para uma leitura lexical, estando de acordo com a posição de Share (1995) a respeito da "lexicalização" progressiva da rota fonológica no curso do desenvolvimento da leitura. As crianças de $3^{a}$ série, com um ano a mais de ensino formal de leitura do que as crianças de $2^{\mathrm{a}}$ série, já haviam internalizado um extenso vocabulário ortográfico que proporcionaria um melhor uso da rota lexical. Mas, concomitantemente, usam a rota fonológica dependendo do material de leitura, principalmente na leitura de itens novos e menos familiares.

Leitores proficientes no uso de ambas as rotas de leitura foram os mais precisos na tarefa de leitura de palavras isoladas, estando capacitados a ler qualquer tipo de estímulo. Leitores que usavam preferencialmente a rota fonológica desempenharam esta tarefa com maior precisão do que leitores preferencialmente lexicais, o que pode ser justificado pelo fato da rota fonológica também permitir a leitura de qualquer tipo de estímulos, podendo trazer problemas apenas na leitura de palavras irregulares, que podem ser regularizadas. Este resultado aponta, mais uma vez, para a importância da rota fonológica para a leitura de palavras. Leitores preferencialmente lexicais podem ter uma leitura mais rápida, pela automaticidade do acesso ao léxico, mas apresentam sérias dificuldades na leitura de palavras não-familiares e de pseudopalavras.

A rota fonológica parece essencial principalmente no início do desenvolvimento da leitura, assumindo, segundo Alégria e colaboradores (1997), o papel motriz deste desenvolvimento. Portanto, se a associação grafema-fonema for deficiente, todo o processo de desenvolvimento poderá estar comprometido. Esta afirmação torna-se de vital 
importância para o ensino da leitura na escola, já que reforça a necessidade do ensino de habilidades de decodificação.

Portanto, em geral, as crianças estudadas usavam ambas as rotas de leitura de palavras. No leitor normal as duas vias estão disponíveis (Morais, 1996).

Com um ano a mais de escolaridade, as crianças já entraram em contato com diferentes tipos de materiais escritos, possibilitando a expansão de seu léxico mental e o aperfeiçoamento de ambas as rotas de leitura de palavras. Outra questão a ser considerada é que na escola, muitas vezes, há um controle do vocabulário exposto às crianças, ou seja, as palavras irregulares (exceções) poderiam ter sido aprendidas mais tarde.

Uma hipótese que poderia explicar a superioridade das crianças mais novas em relação àquelas com idade superior a 8 anos na leitura de pseudopalavras seria que a maioria delas, por estarem ainda usando preferencialmente a rota fonológica ou ambas, têm melhores condições de ler precisamente pseudopalavras através da aplicação de regras de correspondência grafema-fonema. As crianças mais velhas, nas quais há uma maior proporção que usa a rota lexical predominantemente, fariam uma leitura global destes estímulos, incorrendo em erros do tipo neologismo ou lexicalização.

Os erros de lexicalização foram significativamente mais freqüentes $(F(1,70)=6,22 ; p<0,05)$ em alunos da $3^{\text {a }}$ série $(m=10,72 \%)$ do que alunos da $2^{\mathrm{a}}$ série $(m=3,04 \%)$. Isto evidencia que os primeiros, pelo fato de maior número de sujeitos usarem preferencialmente a rota lexical ou ambas, tornam-se mais susceptíveis a cometer erros de lexicalização, podendo indicar um mecanismo de adivinhação pelo contexto interno/gráfico da palavra, ou seja, uso parcial da informação ortográfica. Na leitura por rota fonológica esse tipo de erro é mais difícil de ocorrer, pois a atenção do sujeito é distribuída igualmente para todos as letras da palavra.

\section{Compreensão e Tempo de Leitura Textual}

Proposições dentro de uma história são ordenadas hierarquicamente. A amostra deste estudo relatou maior número de macroproposições do que de microproposições menos relevantes da história. Elementos de níveis mais altos da hierarquia (macroproposições) têm maior probabilidade de serem lembrados e incluídos em resumos (Kintsch, 1998). Os 4 grupos de leitores apresentaram desempenhos em compreensão de leitura relativamente semelhantes, exceto na $3^{\mathrm{a}}$ série. $\mathrm{Na}$ amostra de $3^{\mathrm{a}}$ série, houve diferença significativa no número de interferências entre os grupos de leitores $(F(3,32)=7,71 ; p<0,01)$. O Grupo PF apresentou o maior número de interferências $(m=5,0)$, enquanto o restante dos grupos não diferiu significativamente entre si. As médias do número de interferências presentes nos recontos dos Grupos BA, PL e MA foram, respectivamente, 1,20; 1,20 e 0,50 . Este dado pode sugerir que, nas crianças de $3^{a}$ série, o uso preferencial da rota fonológica pode comprometer, de uma certa forma, a compreensão e retenção de história lida. Talvez por ser uma rota mais lenta de acesso ao léxico e, conseqüentemente, requerer maior carga de memória de trabalho e atenção consciente neste processo mais básico, o uso desta estratégia permitiria a interferência de elementos dentro da história, modificando o significado da mesma.

Esses resultados sugerem que as habilidades compreensivas e de memória de curto prazo das crianças melhoram com a escolaridade, o que pode também estar relacionado ao progresso no uso de estratégias metacognitivas.

Ao contrário deste estudo, Freebody e Byrne (1988), constataram que o grupo de bons leitores por ambas as rotas desempenhou significativamente melhor as tarefas de compreensão de leitura do que os leitores proficientes no uso de apenas uma das rotas e do que maus leitores por ambas as rotas. Os autores sugerem que boa habilidade de identificação de palavras estaria subjacente a uma boa compreensão da leitura. No estudo aqui apresentado, diferente do de Freebody e Byrne, uma pequena parcela da amostra apresenta dificuldades no reconhecimento de palavras isoladas por ambas as rotas $(11,8 \%)$.

Os resultados de tempo de leitura textual evidenciam que as crianças com melhores habilidades de leitura de palavras foram as que leram o texto com maior velocidade, ou seja, nestas a leitura de palavras está mais automatizada. Esse dado aponta para a relação entre automatismo em leitura de palavra isoladas e velocidade de leitura de texto. $\mathrm{O}$ acesso preciso e rápido (automático) ao léxico mental influencia no tempo gasto na leitura de um texto.

Os grupos que usavam preferencialmente uma das rotas de leitura de palavras (Grupos PF e PL) foram significativamente mais lentos na leitura do que alunos que usavam ambas as rotas de forma eficiente (Grupo BA). Isto demonstra que o leitor proficiente não é aquele que usa preferencialmente a rota lexical ou de acesso direto ao léxico mental, mas aquele que é capaz de usar adequadamente ambas as rotas, dependendo das demandas da tarefa.

Salienta-se, ainda, que outros fatores podem influenciar na velocidade de leitura textual, além da competência na leitura de palavras, como a capacidade de usar a informação semântica contextual. Morais (1996) refere que, mesmo entre os leitores hábeis, existe uma ampla variabilidade na velocidade de leitura, que está ligada à uma série de fatores em relação a diferenças individuais nas estratégias cognitivas de tratamento de informação. 


\section{Correlações entre as Avaliações}

A correlação encontrada entre leitura de palavras isoladas e compreensão de leitura pode ser justificada pelo fato da habilidade de leitura de palavras ser considerada básica para a compreensão de um texto. A magnitude da correlação pode ser justificada, segundo Braibant (1997), pelo fato de a compreensão escrita não se reduzir à simples decodificação de palavras. Certamente, outros fatores influenciam o nível de compreensão textual. Segundo Palmer, MacLeod, Hunt e Davidson (1985), há dimensões distintas, embora correlacionadas, da habilidade de manejar os componentes lexicais e semântico-sintáticos de leitura, mas isto não significa que os diferentes processos sejam necessariamente executados seqüencialmente.

Outra justificativa para a fraca correlação entre estas duas habilidades é de ordem metodológica. $\mathrm{Na}$ tarefa de leitura de palavras isoladas foi medida a precisão na leitura dos estímulos e não o tempo de resposta, ou seja, a rapidez na identificação dos estímulos. Segundo Perfetti e Hogaboam (1975), rápida e eficiente (automatizada) leitura de palavra é um importante fator na leitura com compreensão. Neste trabalho, foi medido apenas o critério eficiência. A relação entre velocidade de identificação de palavra e compreensão não foi estudada diretamente.

Rupley e Willson (1997) encontraram fortes correlações entre os escores em tarefas de reconhecimento de palavras e em compreensão de leitura em crianças entre 6 e 9 anos de idade. Os autores salientam que a relação entre estas habilidades começa a declinar levemente apenas nas crianças de 10-12 anos de idade.

A correlação encontrada entre a leitura de palavras regulares, irregulares e pseudopalavras sugere que ambas as rotas de leitura de palavras, fonológica e lexical, estão relacionadas e desenvolvem-se juntas. Segundo Morais (1996), a correlação entre a medida da decodificação (rota fonológica) e a medida do acesso ortográfico (rota lexical) é geralmente mais elevada nos leitores normais do que nos leitores deficientes, o que sugere que o desenvolvimento de representações ortográficas precisas depende de uma boa capacidade de decodificação. Tal capacidade permite ao leitor concentrar sua atenção nos detalhes da ortografia.

\section{Conclusões}

Pode-se concluir, com estes resultados, que os Modelos Cognitivos de Leitura de Dupla-Rota, elaborados no contexto da língua inglesa, mostraram-se válidos para descrever as estratégias de leitura de palavras de uma amostra de crianças brasileiras em início de $2^{\mathrm{a}} \mathrm{e}$ $3^{a}$ séries. Há várias evidências apontando que a rota fonológica parece estar melhor desenvolvida e ser mais amplamente usada pela amostra estudada do que a rota lexical, que está em construção, sugerindo um processo de desenvolvimento das habilidades de leitura. Não houve leitores exclusivamente fonológicos ou leitores exclusivamente lexicais, o que indicaria casos patológicos (dislexia) em uma abordagem de processamento da informação.

A rota fonológica parece essencial principalmente no início do desenvolvimento da leitura. Crianças que usavam preferencialmente esta rota apresentaram desempenho significativamente superior em leitura de palavras isoladas ao daquelas que usavam preferencialmente a rota lexical. As habilidades de reconhecimento de palavras isoladas correlacionaram-se significativamente com habilidade de compreensão de leitura textual e com tempo de leitura em contexto.

Os dados encontrados neste estudo dão apoio empírico para os modelos de dupla rota de leitura de palavras, dentro de uma abordagem de processamento da informação. Estes modelos cognitivos de leitura podem ser usados para avaliar as habilidades específicas das crianças com desenvolvimento normal e daquelas com dificuldades de leitura e, adicionalmente, podem ser usados para desenvolver e avaliar programas de intervenção com base cognitiva. Apenas com uma avaliação de cada um dos processos cognitivos envolvidos na habilidade de ler podemos melhor compreender a aquisição normal e anormal das habilidades de leitura e sugerir abordagens de ensino mais adequadas ao desenvolvimento.

A abordagem de processamento da informação é ainda pouco conhecida em nosso meio e esse desconhecimento, segundo Pinheiro (1995), deve-se à justificada preocupação com o estudo da totalidade psicológica. Concordamos com esta autora quando relata que para compreendermos o funcionamento de atividades humanas específicas, tais como a linguagem (falada e escrita), torna-se inevitável recorrermos a uma abordagem específica, objetiva e analítica, que focaliza os processos mentais envolvidos na atividade lingüística, tentando oferecer assim um relato detalhado e explícito desses processos cognitivos.

\section{Referências}

Alégria, J., Leybaert, J. \& Mousty, P. (1997). Aquisição da leitura e distúrbios associados: Avaliação, tratamento e teoria. Em J. Grégoire \& B. Piérart (Orgs.), Avaliação dos problemas de leitura: Os novos modelos teóricos e suas implicações diagnósticas (pp. 105-124). Porto Alegre: Artes Médicas.

Braibant, J. (1997). A decodificação e a compreensão: Dois componentes essenciais da leitura no $2^{\circ}$ ano primário. Em J. Grégoire \& B. Piérart (Orgs.), Avaliação dos problemas de leitura: Os novos modelos teóricos e suas implicações diagnósticas (pp. 167-187). Porto Alegre: Artes Médicas.

Brandão, A. C. P. \& Spinillo, A. G. (1998). Aspectos gerais e específicos na compreensão de textos. Psicologia: Reflexão e Crítica, 11, 253-272. 
Bub, D. \& Gum, T. (1988). Psychlab software. Montreal: McGill University.

Capovilla, A. G. S. \& Capovilla, F. C. (2000). Problemas de leitura e escrita: Como identificar, prevenir e remediar numa abordagem fônica. São Paulo: Memnon.

Cardoso-Martins, C. (1991). A sensibilidade fonológica e a aprendizagem inicial da leitura e da escrita. Cadernos de Pesquisa, 76, 41-49.

Cardoso-Martins, C. (1995). Consciência fonológica e alfabetização. Petrópolis, Rio de Janeiro: Vozes.

Cielo, C. A. (1996). Relação entre a sensibilidade fonológica e a fase inicial da aprendizagem da leitura. Dissertação de Mestrado não-publicada, Pontifícia Universidade Católica do Rio Grande do Sul. Porto Alegre, RS.

Denhière, G. \& Baudet, S. (1992). Lecture comprébension de texte et science cognitive. Paris: Presses Universitaires de France.

Ellis, A. W. (1995). Leitura, escrita e dislexia: Uma análise cognitiva. Porto Alegre: Artes Médicas.

Freebody, P. \& Byrne, B. (1988). Word-reading strategies in elementary school children: Relations to comprehension, reading time, and phonemic awareness. Reading Research Quarterly, 23(4), 441-453.

Hillis, A. E. \& Caramazza, A. (1992). The reading process and its disorders. Em D. I. Margolin (Org.), Cognitive neuropsychology in clinical practice (pp. 229-261). New York, Oxford: Oxford University Press.

Johnson, R. A. \& Wichern, D. W. (1998). Applied multivariate statistical analysis. New Jersey: Prentice Hall.

Kato, M. A. (1999). O aprendizado da leitura. São Paulo: Martins Fontes.

Kintsch, W. (1977). On comprehending stories. Em M. Just \& P. Carpenter (Orgs.), Cognitive process in comprehension (pp. 33-62). Hillsdale: Lawrence Erlbaum.

Kintsch, W. (1998). Comprehension: A paradigm for cognition. New York: Cambridge University Press.

Kintsch, W. \& van Dijk, T. A. (1978). Toward a model on text comprehension and production. Psychological Review, 85(5), 363-394.

Lecours, A. R., \& Parente, M. A. M. P. (1997). Dislexia: Implicações do sistema de escrita do português. Porto Alegre: Artes Médicas.

Morais, J. (1996). A arte de ler. São Paulo: Editora da Universidade Estadual Paulista.

Palmer, J., MacLeod, C. M., Hunt, E. \& Davidson, J. E. (1985). Information processing correlates of reading. Journal of Memory and Language, 24, 59-88.

Parente, M. A. M. P., Capuano, A. \& Nespoulous, J. (1999). Ativação de modelos mentais no recontar de histórias por idosos. Psicologia: Reflexão e Crítica, 12(1), 157-172.
Parente, M. A. M. P., Silveira, A. \& Lecours, A. R. (1997). As palavras do português escrito. Em A. R. Lecours \& M. A. M. P. Parente (Orgs.), Dislexia: Implicações do sistema de escrita do português (pp. 41-55). Porto Alegre: Artes Médicas.

Perfetti, C. A. (1992). A capacidade para a leitura. Em R. Sternberg (Org.), As capacidades intelectuais humanas: Uma abordagem em processamento de informações (pp. 72-96). Porto Alegre: Artes Médicas.

Perfetti, C. A. \& Hogaboam, T. (1975). Relationship between single word decoding and reading comprehension skill. Journal of Educational Psychology, 67 (4), 461-469.

Pinheiro, A. M. V. (1994). Leitura e escrita: Uma abordagem cognitiva. Campinas: Editorial Psy.

Pinheiro, A. M. V. (1995). Dificuldades específicas de leitura: A identificação de déficits cognitivos e a abordagem do processamento de informação. Psicologia: Teoria e Pesquisa, 11(2), 107-115.

Pinheiro, A. M. V. (1996). Contagem de freqüência de ocorrência de palavras expostas a crianças na faixa de pré-escola e séries iniciais. Software produzido pela Associação Brasileira de Dislexia - ABD.

Pinheiro, A. M. V. \& Parente, M. A. M. P. (1999). Estudo de caso de um paciente com dislexia periférica e as implicações dessa condição nos processamentos centrais. Pró-Fono Revista de Atualização Científica,11 (1), 115-123.

Rego, L. L. B. (1995). Diferenças individuais na aprendizagem inicial da leitura: Papel desempenhado por fatores metalingüísticos. Psicologia: Teoria e Pesquisa, 11(1), 51-60.

Rocha, R. (1997). A coisa. Em C. S. Carvalho \& M. D. Baraldi (Orgs.), Construindo a escrita: Leitura e interpretação de textos (pp. 86-87). São Paulo: Ática.

Rupley, W. H., \& Willson, V. L. (1997). Relationship between comprehension and components of word recognition: Support for developmental shifts. Journal of Research and Development in Education, 30 (4), 255-260.

Share, D. L. (1995). Phonological recoding and self-teaching: Sine qua non of reading acquisition. Cognition, 55, 151-218.

Sobre as autoras

Jerusa Fumagalli de Salles é Fonoaudióloga, Especialista em Linguagem pelo CFFa ( $\mathrm{n}^{\circ}$ 1716/ 02). Mestre e Doutoranda em Psicologia do Desenvolvimento pela Universidade Federal do Rio Grande do Sul (UFRGS). Professora do Curso de Psicologia do Centro Universitário Franciscano, UNIFRA.

Maria Alice de Mattos Pimenta Parente é Fonoaudióloga, Doutora em Psicologia pela USP, PósDoutora pelo Centre de Recherche du Centre Hôspitalier "Côte-des-Neiges", Universidade de Montreal, Canadá. Professora do Instituto de Psicologia da Universidade Federal do Rio Grande do Sul, UFRGS. 